\title{
$>$ Notas sobre a influência platônica em Michelangelo
}

\author{
> Some remarks about the platonic influence in Michelangelo
}

\section{por Laura Elizia Haubert}

Mestre em Filosofia pela Pontifícia Universidade Católica de São Paulo. E-mail eliziahaubert@gmail.com. ORCID: 0000-0002-7323-441X.

\begin{abstract}
Resumo
A presente pesquisa visou a explorar brevemente as relações entre as obras do jovem Michelangelo e a influência teórica do platonismo e neoplatonismo que se disseminaram em Florença durante a época de Lorenzo, o Magnífico. Para empreender o projeto com clareza, dividiu-se a abordagem em quatro momentos, sendo eles: i) uma introdução geral; ii) o cenário Florentino e a filosofia platônica; iii) a filosofia platônica, seus principais pontos e a recuperação de seus conceitos pelos humanistas renascentistas; e iv) a influência platônica sobre o jovem Michelangelo. Assim, buscou-se, sem pretensões de esgotar o tema, demonstrar em que medida as formas artísticas de Michelangelo e suas concepções filosóficas estão profundamente interligadas.
\end{abstract}

Palavras-chave: Platão. Neoplatonismo. Arte. Michelangelo. Humanismo.

\begin{abstract}
This research aimed to briefly explore the relationship between the works of young Michelangelo and the theoretical influence of Platonism and neoplatonism that spread in Florence during the time of Lorenzo the Magnificent. To undertake the project clearly, the approach was divided into four stages, namely: i) a general introduction; ii) the Florentine scenario and the Platonic philosophy; iii) Platonic philosophy, its main points and the recovery of its concepts by Renaissance humanists; and iv) the Platonic influence on the young Michelangelo. Thus, we tried without pretending to exhaust the theme to demonstrate to what extent Michelangelo's artistic forms and his philosophical conceptions are deeply interconnected.
\end{abstract}

Keywords: Plato. Neoplatonism. Art. Michelangelo. Humanism. 


\section{Introdução}

A Renascença foi um importante período de retomada dos estudos da Grécia antiga, ao mesmo tempo que nutriu uma rejeição da escolástica medieval. É de conhecimento comum que as novas pontes entre o Império Bizantino e o oeste latino, no século XV, resultaram em um redescobrimento do corpus da obra platônica e sua primeira grande divulgação desde o encerramento da Academia.

De fato, parte considerável do mérito de tornar acessível Platão a estes homens do século XV deve-se a Marsilio Ficino que foi patrocinado pela família Medici em Florença e, durante os anos de 1463 a 1469, traduziu as obras de Platão para o Latim, em uma edição que veio a público em $1484{ }^{1}{ }^{1}$

A obra de Ficino continha não somente a tradução de Platão, como também de pensadores neoplatônicos como Plotino, além de uma tradição mística hermeneuta, a cabala, e outras fontes que produziram um corpo de pensamento de natureza divergente e extremamente abstrato. ${ }^{2}$ Além destas, a visão platônica florentina também se adequava perfeitamente à verdade e ao método cristão, de modo que todas essas crenças funcionavam em uma espécie de unidade da verdade.

Vale ressaltar que a Accademia Platonica estabelecida por Ficino tinha três objetivos básicos, a saber: (i) visava tornar acessível os textos platônicos por meio de traduções; (ii) visava trabalhar em um enorme cabedal que formava um sistema filosófico; e (iii) era importante que todo esse sistema filosófico platônico e neoplatônico fosse harmonizado com a fé cristã em um humanismo.

\footnotetext{
${ }^{1}$ Kenneth Bartlett, The Civilization on the Italian Renaissance: a sourcebook, 2011.

${ }^{2}$ É importante destacar que, para Ficino e seus contemporâneos, o projeto incluía não só a tradução de Platão, mas também de pensadores neoplatônicos como Plotino, Proclo, Porfírio, Jâmblico e Pseudo-Dionísio Areopagita. Esses pensadores eram tratados com a mesma relevância de Platão, de fato, antes de Leibniz, não havia uma diferenciação precisa entre o que era o pensamento de Platão e o que era neoplatônico. Cf. Ronel Alberti da Rosa, A sombra de Orfeu: o neoplatonismo renascentista e o nascimento da ópera, 2010.
} 
O resultado desse intento foi que o neoplatonismo floresceu na Renascença italiana entre os eruditos e círculos aristocráticos, não compondo parte essencial dos estudos nas universidades. ${ }^{3}$ Esse sistema filosófico foi explorado por diversos escritores, poetas e pintores da época, como no caso de Michelangelo, cuja primeira fase é marcadamente influenciada pelo contexto neoplatônico, sobretudo sua compreensão sobre o nu, como ver-se-á melhor abaixo.

Para compreender algumas das características platônicas de Michelangelo, buscou-se compreender melhor a situação da filosofia platônica no cenário florentino, o impacto de Marsilio Ficino, e assim, por último, retornar ao pintor e escultor analisando alguns dos traços de Michelangelo que demonstram sua adesão a essa corrente filosófica.

\section{O cenário florentino: a recepção platônica}

Ainda que não se possa afirmar que a Renascença foi uma era platônica, não obstante é claro que a filosofia de Platão foi recuperada e ganhou prestígio novamente durante esse período. ${ }^{4}$ Sua influência se estendeu de Petrarca a Ficino, sendo esta a primeira grande retomada de sua filosofia desde o fechamento da Academia por Justiniano em 529 d.C. ${ }^{5}$

Essa nova onda de interesse pela filosofia platônica está atrelada, primeiramente, ao número de traduções que começaram a aparecer no século $\mathrm{XV}$ em suas versões mais completas. Até então, os medievais conheciam versões

\footnotetext{
${ }^{3}$ Kenneth Bartlett, The Civilization on the Italian Renaissance: a sourcebook, 2011.

4 A respeito de teorias da recepção dos clássicos, consultar: Anastasia Bakogianni, O que há de tão clássico na recepção dos clássicos? Teorias, metodologias e perspectivas futuras, in Codex, 2016, p. 114-131. Lorna Hardwick, Reception Studies. Greece \& Rome, in New Surveys in the Classics. N ${ }^{\circ}$ 33. Oxford: Oxford University Press, 2003.

Ana Isabel Martins, Recepção do mundo epistêmico da Antiguidade na historiografia renascentista (performance humanista): as Collectaneas e os loci communes, in Classica (Brasil). V. 23, n. 1/ 2, 2010, pp. 132-142.

5 James Hankins, Plato in the Italian Renaissance, 1990.
} 
parciais do Timeu, por meio de Cícero e Calcídio, e alguns trechos de outras obras copiadas por Cícero. Também conheceram partes de outros diálogos, às vezes, com trechos quase inteligíveis, como no caso do Fédon e do Mênon, que haviam sido traduzidos no século XII por Henricus Aristippus, ou a versão incompleta de Parmênides traduzida no século XIII. ${ }^{6}$

É notório que, no século $\mathrm{XV}$, o cenário começou a se modificar favoravelmente, na figura dos humanistas, como Leonardo Bruni, Uberto Decembrio e Cencio De' Rustici, que traduziram os diálogos de Platão incluindo Górgias, Crito, Apologia, Phaedro e a República completos. Essas traduções tiveram sua culminação no trabalho de Marsilio Ficino, que, em 1484, tinha uma versão completa dos trabalhos platônicos em latim e, em 1496, publicou uma série de anotações e comentários a eles.7

As traduções são apenas uma parte dessa retomada do platonismo; é preciso observar ainda o surgimento de uma nova retórica inspirada por Platão, como no caso de autores tais como Petrarca e Francesco Patrizi da Cherso. Ademais, há, no final do século XV, o ressurgimento do platonismo cristão como escola filosófica. ${ }^{8}$

A retomada dos filósofos gregos, em especial Platão e os neoplatônicos, assemelhava-se, no contexto florentino, a um novo ponto de partida para os humanistas, principalmente porque uma novidade do humanismo florentino no tempo de Lourenço foi a superação da tradição moral de Salutati e da escolástica. Voltava-se então a Homero, Hesíodo e Platão. ${ }^{9}$

Faz-se necessário observar, não obstante, que essa influência é também um cabedal no qual se mesclam vários componentes, porque para o pensamento do homem renascentista não havia uma diferença entre os pensadores da Grécia

\footnotetext{
${ }^{6}$ Ibidem.

${ }^{7}$ Ibidem.

${ }^{8}$ Ibidem.

${ }^{9}$ André Chastel, Arte e humanismo em Florença na época de Lourenço, o Magnífico: estudos sobre o Renascimento e o Humanismo platônico, 2012.
} 
clássica de Platão e Aristóteles, daquelas influências do que reconhecemos como um helenismo tardio, e até mesmo de influências orientais, como se nota em Proclo ou Jâmblico. O ponto é que Platão constituia basicamente a grande novidade a ser recuperada. ${ }^{10}$

É preciso questionar o que esse retorno à Antiguidade significou no contexto florentino. Com efeito, se o retorno à filosofia clássica é um traço importante, ela o é porque significou não apenas uma mudança no panorama da cultura aristocrática, mas também porque representou uma ausência de perspectiva histórica, como de fato observa-se abaixo:

[...] o terceiro traço característico do humanismo florentino é a ausência de perspectiva histórica, ou melhor, a tendência a abraçar o pensamento e a arte antigos em uma construção ideal que culmina no platonismo, e darlhe por único confronto o mundo moderno, orientando pela revolução espiritual em curso. [...]. Os mestres da escolástica não são, evidentemente, ignorados nem menosprezados; são tratados como exceções em idades sem cultura, e não atrapalham o movimento natural dos humanistas, que é de ligar o século XV ao final da Antiguidade. Ghiberti declarava igualmente, em seus Commentarii, que passando sobre dez séculos de desvio ou, em todo caso, de imobilidade, a pintura, a escultura, a arquitetura "modernas" tinham recuperado a força dos antigos, tal como ela ainda se manifestava no final do Império Romano. Em sua cronologia, o século XV dá continuidade ao século IV. ${ }^{11}$

À luz dessa interpretação, observou-se que um traço do humanismo florentino foi a ausência de perspectiva histórica, porque os autores e artistas da época buscavam conectar sua era à Antiguidade, ignorando a Idade Média e tudo que tinha sido desenvolvido nessa época como algo menor ou de pouca importância. Para esses humanistas, era chegada a hora de retomar a vitalidade dos gregos e romanos, ao menos no campo das artes.

O anseio pelo retorno à filosofia platônica e à vigorosa arte romana e grega está intrinsecamente relacionado à situação política de Florença durante esse período da história. Recorde-se que o chefe à frente de Florença era Lorenzo, o magnífico (1449-92), neto de Cósimo de Médici, que assumiu o controle da cidade

\footnotetext{
${ }^{10}$ Ronel Alberti da Rosa, A sombra de Orfeu: o neoplatonismo renascentista e o nascimento da ópera, 2010.

${ }^{11}$ Ibidem, p. 142.
} 
em 1434. Ele foi um famoso patrono das artes e um grande amigo dos humanistas, como Pico della Mirandola, Marsilio Ficino, Sandro Boticelli, Michelangelo e Angelo Poliziano, para citar alguns. Era um colecionador interessado em antiguidades, além de um escritor/poeta. Seu regime marca um momento de interrupção da vida cívica livre.

Com efeito, a recepção de Platão no início do Renascimento reflete dois estágios diferentes da realidade política vivenciada. Em um primeiro momento, que corresponderia à época de Petrarca a Bruni, a sociedade florentina ainda é relativamente aberta e a forma da comuna medieval não perdeu completamente sua força; o Platão recuperado por esses autores é, principalmente, o de caráter crítico e aberto, que prioriza o diálogo; em contraponto, no segundo estágio, que vai desde o Concílio de Florença, entre 1438-39, até o fim do século, há uma mudança política e social que também reflete no platonismo escolhido. Não se trata mais do Platão crítico, mas sim de um Platão religioso e metafísico. ${ }^{12}$

Diante do que foi brevemente exposto, constata-se que o platonismo florentino não pode ser pensado completamente desvencilhado da política de seu período, especialmente no que tange ao segundo momento. A respeito desse período, vide o trecho a seguir:

\begin{abstract}
O regime Médici põe fim à vida cívica livre, e coloca os artistas e literatos sob o feitiço de uma vida de corte artificial centrada, não no espaço cívico aberto, mas na vila suburbana, em uma torre de marfim de ineficácia política. Reduzidos à dependência política, em fuga do mundo, os "intelectuais Médici" olham para Platão para validação de sua experiência. Mas não é o antigo Platão crítico e prático do primeiro período, mas um novo Platão religioso e metafísico. [...] O novo Platão ensina os pensadores do final do século XV a buscar as fontes de poder além da justiça e harmonia; daí, eles buscam no próprio Platão não a crítica social ou o debate aberto, mas uma teologia sistemática, uma nova revelação filosófica. ${ }^{13}$
\end{abstract}

${ }^{12}$ E. Garin, Ricerche sulle traduzioni di Platone nella prima metà del sec. XV, In: Medievo e Rinascimento: studi in onore di Bruno Nardi, 1955.

${ }^{13}$ James Hankins, Plato in the Italian Renaissance, 1990, p. 15. Tradução nossa: "The Medici regime puts an end to free civic life, and places the artists and literati under the spell of an artificial court life centered, not in the open civic space, but in the suburban villa, in an ivory tower of political ineffectiveness. Reduced to political dependency, in flight from the world, the "Medici intellectuals" look to Plato for validation of their experience. But it is not the old critical, practical Plato of the first period, but a new religious, metaphysical Plato. [..] The new Plato teaches the 
O segundo momento do platonismo florentino é marcado por uma inclinação metafísica e religiosa, e não parece casual que Ficino, um dos maiores tradutores de Platão, volte-se também constantemente para temas místicos e religiosos. O Platão a que se reportavam nesse período é aquele responsável por dar prioridade ao mundo das ideias e ao divino.

Ora, que esse tenha sido o movimento da segunda metade do século XV e que tenha se estendido até o fim do século não é meramente casual. ${ }^{14}$ Lorenzo, o Magnífico tinha grandes interesses políticos e intelectuais pelo neoplatonismo. ${ }^{15}$ O neoplatonismo e o idealismo platônico nas artes desse período florentino são expressões de uma atitude reservada frente ao mundo, serviram para encaminhar os pensadores em direção não ao racionalismo, mas sim há uma atitude mais mística. ${ }^{16}$ Trata-se de uma leitura particular de Platão, na qual se busca evidenciar uma renúncia às coisas do mundo, assim, o filósofo - e nesse caso também o artista - somente se esforça para morrer, e assim finalmente poder alcançar o mundo intemporal das ideias.

\section{Platão: o impacto nas artes}

Como visto anteriormente, a obra de Platão foi traduzida no século XV e culminou com a publicação das obras completas em latim por Marsilio Ficino no ano de 1484. Ficino teve como patronos os Médici em Florença para conseguir concretizar seu projeto. Ele havia se estabelecido na Villa Medicea di Careggi, um

\footnotetext{
thinkers of the late fifteenth century to look within for the sources of power, to seek in the Beyond for justice and harmony; hence they seek in Plato himself not social criticism or openended debate, but a systematic theology, a new philosophical revelation."

${ }^{14}$ Arnold Hauser, História social da arte e da literatura, 1998.

${ }^{15}$ Sobre a relação entre Lorenzo e o neoplatonismo, chama-se atenção para o fato de que "Talvez o fato de que Leonardo não tivesse absolutamente nada a ver com o movimento neoplatônico explique por que Lorenzo não mostrou qualquer interesse por ele". Isto porque "É óbvio que essa filosofia atraía inevitavelmente um homem como Lorenzo, que destruíra os últimos vestígios de democracia e reprovava toda e qualquer espécie de ativismo político. Seja como for a doutrina platônica, que é tão fácil de diluir e traduzir em termos puramente poéticos, teria estado de acordo com seu gosto" (Ibidem, p. 314).

${ }^{16}$ Teresa Aline Pereira de Queiroz, O Renascimento, 1995.
} 
palácio pertencente à família Médici, no qual deu início a uma pequena e informal "academia" que incluiu algumas das figuras intelectuais e artísticas mais importantes da época como Giovanni Pico della Mirandola, Angelo Poliziano e Michelangelo. ${ }^{17}$

Marsilio Ficino era um dos neoplatonistas mais importantes da Renascença. Conhecia latim, grego e medicina quando foi empregado por Cosimo de' Medici para traduzir o corpus platônico entre os anos de 1463 e 1469. Segundo os registros, Ficino ficara tão fascinado com o pensamento platônico que o julgara superior inclusive ao do Cristianismo. ${ }^{18}$

O espírito platônico metafísico da segunda metade do século e sua ausência de interesse pelo mundo parece ter também sido nutrido no projeto da Academia de Ficino, conforme observa-se a seguir:

Existe um paralelismo notável entre a atitude dos meios artísticos e a dos humanistas contemporâneos. Nos seus momentos de exaltação e confiança Ficino e seus amigos chegavam à ideia de alguma revivescência precisa dos personagens platônicos: o que é ilustrado pelo Banquete de Careggi, inspirado no Symposiom. Sobre essa noção da imitatio Platonis levada até detalhes surpreendentes, Ficino iria construir a história da Academia, no sentido de uma instituição ideal, sempre pronta a se reformar. A cultura se torna, para os platônicos consequentes, uma imensa

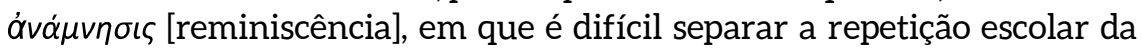
redescoberta interior. Essa orientação iria contribuir para alimentar a ideia de que a cultura não deve cristalizar-se nas universidades, menos ainda nos conventos, mas sim em centros livremente organizados, de que a Academia chareggiana oferece o exemplo. Daí o valor estimulante, porém impreciso, do próprio termo academia, que seria, por fim, utilizado para designar as reuniões de artistas interessados na cultura e na doutrina - além das preocupações do ateliê. [... $]^{19}$

Conforme observa-se, há um paralelismo que se apresenta entre os humanistas florentinos e o que estava sendo realizado na arte naquele momento. A presença de Platão é indubitável no meio intelectual, e as recriações do 'Banquete', ou mesmo da Academia, apontam para o que o autor chamou de imitatio Platonis. A cultura passou a ser compreendida em termos de

\footnotetext{
${ }^{17}$ Kenneth Bartlett, Op. Cit., 2011.

${ }^{18}$ Ibidem.

${ }^{19}$ André Chastel, Op. Cit., 2012, p. 154 a 155.
} 
reminiscência e de redescoberta, tal como havia proposto o filósofo grego em sua teoria do conhecimento.

Curiosamente, tratando-se de Platão, dentro de seu pensamento, a questão da arte é complexa: Platão apresenta ora atração ora repulsa pela arte. Primeiro, porque não há um único diálogo que trate da beleza ou da arte, o tema aparece aqui e ali em passagens de vários diálogos; depois, porque Platão não desenvolveu propriamente uma teoria da arte, apenas notações dispersas sobre a prática do que, na antiguidade, chamava-se de téxvn (tekné). ${ }^{20}$

Com efeito, em todo o corpus platônico, excetuando talvez o diálogo Hippias Maior, não há no restante a apresentação dos temas da arte e da beleza tratados por si mesmos. Certamente há trechos no diálogo da República, Íon e Banquete, mas nesses a arte não é o objeto principal e aparece apenas de revés na reflexão sobre outros objetos ou na crítica à poesia.

Em geral, poder-se-ia colocar para Platão, em destaque, as artes canonizadas, isto é, a arte egípcia, cretense e grega. ${ }^{21}$ Porque elas se aproximavam das formas eternas e imutáveis, mas ainda pertenciam, de modo geral, ao mundo sensível, sendo alteradas pelo tempo. Essas artes geram uma ilusão, a qual é justamente o ponto de vista particular do artista sobre o mundo, a arte enquanto $\mu$ í $\mu$ пı (mímesis) permanece incapaz de dar conta da ideia.

Essa incapacidade da $\mu$ í $\mu \eta \sigma \varsigma$, de dar conta da beleza, sucede porque a beleza começa nos domínios do inteligível, uma vez que há também uma forma ideal de beleza, que é a que interessa propriamente a Platão. Assim, mais do que qualquer outra propriedade, "[...] a beleza envolve a alma e a leva à deliberação filosófica, em direção a pensamentos de beleza absoluta, e subsequentemente, [...]

\footnotetext{
${ }^{20}$ Anne Cauquelin, Teorias da Arte, 2005.

${ }^{21}$ Caroline Combronde, Les Platoniciens de l'art à la Renaissance in Revue Philosophique de Louvain, Quatrième série, tome 97, n 2, p. 268 a 288, 1999.
} 
em direção a pensamentos de outros conceitos"22. De fato, na estética platônica há uma beleza que não se contrapõe ao filosofar e à verdade..$^{23}$

Com efeito, na estética platônica, o homem que produz a arte deve ser capaz de ir além, para reivindicar a universalidade das ideias (eidos). Platão condena a arte enquanto manifestação, não obstante, ele manifesta uma inclinação para a beleza etérea, ou seja, a beleza de cores e de formas puras, geométricas e de manifestação claramente influenciada pelo mundo superior das ideias. Se livrarmos a arte da mera representação do natural, a beleza passa a ter residência também no ideal. ${ }^{24}$

Curiosamente, do Fedro à República e ao Timeu há um certo desenvolvimento da reconciliação do problema entre o reino do sensível com o reino das formas puras, por meio da matemática. O trabalho que emerge das mãos do artesão deve mostrar parte de um ideal, não imitar o mero sensível individual. Não imitar aquilo que está a sua frente, mas antes imitar uma forma ideal. Por exemplo, se criar um tear, ele não está copiando um tear existente, mas sim a partir de um tear ideal. ${ }^{25}$

Assim como na matemática, na arte, a ideia de unidade foi interpretada erroneamente. A verdadeira unidade não resulta do mero acúmulo de semelhanças entre indivíduos diferentes, ela pertence a uma instância pura que se afasta do mero sensual. Assim, "Platão traça a fronteira entre espectadores meramente curiosos, que se contentam com a observação de muitas e belas coisas diversas, e aqueles videntes verdadeiros que penetram a própria forma

\footnotetext{
22 Nickolas Pappas, Plato's Aesthetics, in Edward Zalta, The Stanford Encyclopedia of Philosophy, 2017. Tradução nossa: "[...] beauty engages the soul and draws it toward philosophical deliberation, toward thoughts of absolute beauty and subsequently [...] toward thoughts of other concepts."

${ }^{23}$ Ibidem, p. 4.

${ }^{24}$ Caroline Combronde, Op. Cit., 1999.

${ }^{25}$ Ernst Cassirer, Eidos and Eidolon: the problem of beauty and art in the dialogues of Plato In Ernst Cassirer, The Warburg Years (1919-1933): essays on language, art, myth, and technology, 2013.
} 
originária da beleza"26. Os primeiros sabem reagir e distinguir a beleza assim como os que sonham, dos que estão acordados. ${ }^{27}$

A forma mais pura da beleza é então matemática e a criação artística, a partir da reprodução das Formas Ideais matemáticas, confere ao artista poder semelhante àquele de que o próprio demiurgo dispõe. ${ }^{28}$ Por isso, para Platão, quando Fídias criou Zeus sem usar nenhum modelo sensual individual, ele deu à figura de Zeus algo que o próprio deus teria dado, se estivesse ali encarnado. Ele não meramente reproduziu o mundo, mas criou algo, tal como o demiurgo divino o faz, a partir das ideias.

Sobre as artes na Florença da época e o ideal de beleza matemático herdado de Platão, vide o excerto a seguir:

\begin{abstract}
O recurso à matemática confirma-se como operação constitutiva de toda arte elevada: assegura-se a organização metódica, clara, racional, mas em uma perspectiva mais complexa. O número põe o espírito em comunicação com os 'arcanos' de que trata a 'filosofia socrática e pitagórica'; e a ordem elaborada pelo pintor, escultor ou arquiteto deveria estar ligada a uma simbólica universal. Essa exigência confusa vai adquirindo um peso cada vez maior no final do século XV: ela pode modificar sensivelmente as intenções do artista. O princípio de interrogar diretamente a natureza, perdeu sua simplicidade. ${ }^{29}$
\end{abstract}

Conforme analisou-se, a matemática era um recurso ao qual os artistas se voltavam para moldar sua obra e que dispunha de peso suficiente para inclusive alterar suas intenções. É da matemática e do número, sob uma influência da

\footnotetext{
${ }^{26}$ Ibidem, p. 232. Tradução nossa: "Plato sharply draws the border between merely curious onlookers, who content themselves with the observation of many and diverse beautiful things, and those true seers who penetrate the originary form of beauty itself".

${ }^{27}$ Essa comparação encontra-se na República, vide Platão, A República, 2001, 476c: "Ora quem acreditar que há coisas belas, mas não acreditar que existe a beleza em si nem for capaz de seguir alguém que o conduzisse no caminho do seu conhecimento, parece-te que vive em sonho ou na realidade? Repara bem. Por ventura sonhar não é quando uma pessoa, quer durante o sono, quer deserta, julgar que um objecto semelhante a outro não é uma semelhança, mas o próprio objecto com que se parece?".

${ }^{28}$ Ernst Cassirer, Eidos and Eidolon: the problem of beauty and art in the dialogues of Plato In Ernst Cassirer, The Warburg Years (1919-1933): essays on language, art, myth, and technology, 2013.

${ }^{29}$ André Chastel, Op. Cit., 2012, p. 167.
} 
filosofia socrática e pitagórica, que os pintores, escultores e arquitetos deveriam partir em sua inspiração.

Do que foi dito, observa-se que a questão da beleza e da arte, para Platão, é complexa e fragmentária. Por um lado, enquanto ela aparece na maior parte dos

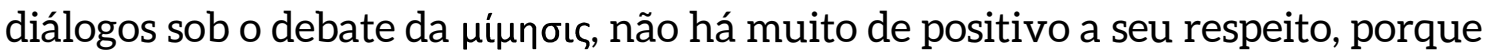
restringe-se à cópia da manifestação dos objetos físicos, estando distante do ideal. Por outro lado, quando aparece relacionada à matemática e à harmonia, embora não possa ser fundida com as formas ideias, participam dela em alguma medida, e por isso possui um status ontológico acima do mero prazer..$^{30}$

Nesse segundo caso, a beleza não é apenas matemática, ela também é boa e nobre. De fato, o conceito de beleza na antiga Grécia fazia parte de uma tríade de valores: o bom, o belo e o verdadeiro. Como escreve Platão, em seu diálogo Lísis: "Com efeito, eu afirmo que o que é bom é belo; tu não achas?"31

A esse respeito, observa-se:

O belo, para Platão, é o rosto do bem e da verdade. São três princípios intimamente ligados: nada pode ser considerado belo se não for verdadeiro; nenhum bem pode existir fora da verdade. Essa tríade é o princípio da ordem que dá acesso à inteligibilidade e sem a qual o mundo seria apenas caos. Esse princípio único (e de unicidade) que dá aos seres sua consistência não pode ser encontrado no diverso, no heterogêneo, no misturado, no sensível, nos fenômenos nem, evidentemente, na arte tal como é praticada. Só o exercício do intelecto permite distingui-lo. ${ }^{32}$

Se a beleza importa, é mais por seu papel desempenhado junto ao bem e à verdade, porque ela está presente neste princípio único que dá consistência ao mundo. Assim, a arte importa propriamente na medida em que pode servir como exercício para o intelecto.

\footnotetext{
30 Julius Moravcsik, Platão e platonismo: aparência e realidade na ontologia, na epistemologia e na ética, 2005.

${ }^{31}$ Platão, Lísis, 2004, p. 216d.

${ }^{32}$ Anne Cauquelin, Teorias da Arte, 2005, p. 30 a 31.
} 
Essa tríade platônica de Bom-Belo-Verdadeiro, conhecida na Grécia antiga

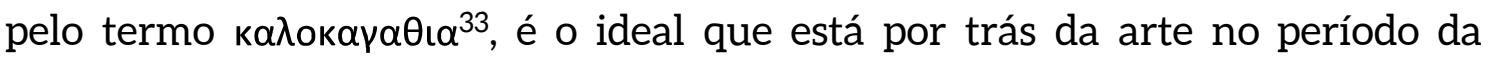
Renascença. Neste, a beleza depende de certo ideal aristocrático e intelectual, em

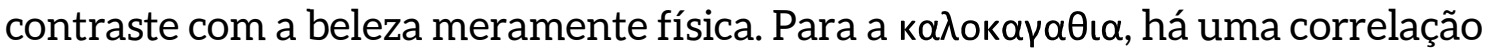
entre beleza e virtude. ${ }^{34}$

De fato, até o final do quattrocento, não havia uma contradição que rompesse os elos entre o bom, o belo e o útil. E "durante o Renascimento os conceitos de medida e de beleza pressupunham um ao outro"35, tal como ocorreu na antiguidade. Novamente, a beleza não só atraía, mas era também objeto do amor, como escrevera Ficino em seu comentário ao diálogo de Platão Banquete, onde amor e beleza aparecem interligados.

Para o homem do Renascimento, e principalmente para o florentino, a medida, assim como o número e a matemática em Platão, está profundamente ligada à criação da beleza e à Forma ideal universal. Desse modo, a beleza refletia o mundo, e, como na antiguidade, era uma afirmação absoluta de um ideal e de um tempo respectivo. ${ }^{36}$

Esse é um ponto curioso e desvela como o ideal de beleza, como medida e como ка入окаүаӨıа, estava enraizado profundamente nesses homens da Renascença, sobretudo em Florença, como se pode contemplar na obra de Botticelli, do jovem Michelangelo, de Leonardo e de Rafael. ${ }^{37}$

A esse respeito, observa-se o excerto:

As artes plásticas demonstram admiravelmente até que ponto o ideal da unidade da beleza exterior e interior prevaleceu durante o primeiro período Medici não só em Florença como ainda, sob influência florentina, em Roma. Dvorak mostrou já a maneira como o estilo da última fase de Donatello se transformou no que toca a seguir o ideal de beleza. Mas eu poderia também referir Botticelli (não apenas o Nascimento de Vênus ou A

\footnotetext{
${ }^{33}$ Barbara Cassin, Dictionary of Untranslatables, 2014, p. 80.

${ }^{34}$ Arnold Hauser, Op. Cit., 1998.

${ }^{35}$ Agnes Heller, O homem do Renascimento, 1982, p. 202.

${ }^{36}$ Ibidem, p. 207.

${ }^{37}$ Ibidem.
} 
Primavera mas também as pinturas de carácter iconográfico, o jovem Miguel Ângelo e Leonardo, ou ainda Rafael. Dvorak analisou igualmente o grau em que o estilo de Rafael, a maniera grande, exprime uma corporeidade ideal, onde não existe conflito entre o corpo e o espírito, na qual prevalece a kalokagathia. Deve sublinhar-se que se trata ainda de uma beleza da medida, mas não do gênero que surge como resultado natural da representação da própria realidade, como vemos em Giotto, Masaccio, ou até em Fra Angelico; trata-se claramente do resultado de um programa. ${ }^{38}$

Curiosamente, esse ideal da beleza como medida e proporção matemática teve sua influência demarcada a um período muito específico e que não se prolongou como na antiga Atenas. Mas foi suficiente para marcar como herdeiros platônicos uma série de artistas que viram a beleza como uma marca do universal celeste, do divino, da contemplação e da matemática. A arte deveria elevar os homens aos céus e, nesse sentido, o jovem Michelangelo não estava distante de seu mestre Ficino, como ver-se-á a seguir.

Em suma, desde a Renascença, surgiu uma nova forma de estética e de teoria da arte que tem suas bases na filosofia platônica e neoplatônica e que buscou nelas sua base teórica para justificação das artes, a partir de diferentes pressupostos de sua doutrina. ${ }^{39}$

\section{O jovem Michelangelo: a influência platônica}

Durante o primeiro período da arte de Michelangelo, que se estende até 1530, suas concepções ideais são as mesmas do Alto Renascimento, isto é, ele reflete a tradição científica da pintura florentina da qual é herdeiro, ao mesmo tempo que espelha a atmosfera neoplatônica que compartilhava na vida intelectual da Academia florentina com seus contemporâneos. ${ }^{4041}$

\footnotetext{
${ }^{38}$ Ibidem, p.207-208.

${ }^{39}$ Ernst Cassirer, Op. Cit., 2013.

${ }^{40}$ Anthony Blunt, La Théorie des Arts en Italie 1450-1600, 1988.

${ }^{41}$ Ibidem. A influência da tradição científica foi herdada de seu período de aprendizado no ateliê de Ghirlandaio, onde ingressara aos treze anos para aprender a arte da pintura.
} 
Esse círculo intelectual, ao qual Michelangelo se integrou ao chegar em Florença, junto a Ficino, Petrarca e outros neoplatônicos, admiradores de Dante e leitores de Salimbene, influenciou seu modo de pensar e produzir arte, ao menos, em um primeiro momento, quando o escultor adere às doutrinas de Platão e à sua forma poética, que vigoravam na Florença do século XV. ${ }^{42}$

É por isso que não se deve estranhar "que o artista tenha uma visão filosófica da sua forma central de expressão poética - a escultura [...]"43. Em verdade, embora ele nos últimos anos chegue a abandonar as concepções platônicas e passe a colocar a arte em primeiro lugar, ele jamais se afastou completamente de uma certa expressão filosófica em sua arte. ${ }^{44}$

Como se observou, que Michelangelo tenha assimilado as concepções platônicas não é excepcional, mas sim o é a forma pela qual ele adotou o sistema em seu todo. A esse respeito, vide o excerto:

Isso não é excepcional. Em um artista italiano do século XVI, a presença de influências neoplatônicas pode ser explicada mais facilmente do que sua ausência seria. Mas entre seus contemporâneos Michelangelo foi o único que adotou o neoplatonismo não em alguns aspectos, mas em sua totalidade, e não como um sistema filosófico convincente, muito menos como uma moda do dia, mas como uma justificação metafísica de si mesmo. Suas próprias experiências emocionais, que alcançaram o primeiro clímax do amor por Tommaso Cavalieri, e o segundo clímax da amizade de Vittoria Colonna, abordaram a ideia do amor platônico em seu sentido mais puro. Enquanto a crença neoplatônica na "presença do espiritual no material" oferecia um pano de fundo filosófico ao seu entusiasmo estético e amoroso pela beleza, o aspecto oposto do neoplatonismo, a interpretação da vida humana como uma forma de existência irreal, desviada e atormentada, comparável para a vida no Hades, ele estava em harmonia com o incomensurável descontentamento de si mesmo e do universo, no qual a própria assinatura do gênio de Michelangelo consiste. Como Piero di Cósimo poderia se considerar o único epicuro genuíno entre os muitos artistas influenciados por Lucrezio, Michelangelo poderia se definir como o único genuíno platônico entre os muitos artistas que o neoplatonismo influenciou. $^{45}$

\footnotetext{
${ }^{42}$ Giorgio Vasari, Vida de Michelangelo Buonarroti, 2011.

${ }^{43}$ Ibidem, p. 482.

${ }^{44}$ Ibidem, p. 482 a 482.

${ }^{45}$ Erwin Panofsky, Il movimento neoplatonico e Michelangelo. Studi di iconologia: I temi umanistici nell'arte del Rinascimento, 1975, p. 4. Tradução nossa: "Tutto ciò non è eccezionale. In un artista italiano del Cinquecento la presenza di influenze neoplatoniche è spiegabile più facilmente di quanto sarebbe la loro assenza. Ma tra i suoi contemporanei Michelangelo fu l'unico che adottò
} 
Conforme mencionado, o excepcional em Michelangelo é que ele adotou o neoplatonismo como uma justificação metafísica para sua arte e para si mesmo. E ele o adotou em diferentes áreas, na arte, mas também em suas convicções pessoais, a respeito de seu amor platônico vivenciado. ${ }^{46}$ Esse sistema apresentou uma via dupla de ganhos para o escultor, uma vez que servia enquanto filosofia para sua estética e seu entusiasmo pela beleza; ao mesmo tempo que servia também para uma interpretação da vida sensitiva como irreal, dolorosa existência da qual ele podia se desviar ao entrar em harmonia com o incomensurável, uma forma de escapismo da realidade.

Munido pelo Platonismo, Michelangelo se coloca como um observador confiante capaz de contemplar o mundo e refleti-lo em sua obra artística. Nesse processo, "a influência do neoplatonismo levou-o a acreditar na beleza do universo, visível sobretudo à beleza humana, sem que o misticismo nostálgico de Florença viesse a colori-lo."47 Suas figuras não são uma mera imitação, mas dependem de fatores mais complexos, são elementos idealizados resultado de estudo e conhecimento avançado da técnica, da matemática e da Forma. A base de sua arte é uma adoração da beleza do corpo humano idealizada.

Com efeito, as obras de Michelangelo refletem sua influência platônica e neoplatônica não somente na forma e nos motivos intelectuais, mas também na

il neoplatonismo non per alcuni aspetti, bensì nella sua totalità, e non come sistema filosofico convincente, e tanto meno come moda del giorno, ma come giustificazione metafisica di se stesso. Le sue proprie esperienze emotive, che avevano raggiunto il primo culmine nell'amore per Tommaso Cavalieri, e il secondo culmine nell'amicizia per Vittoria Colonna, si accostavano all'idea dell'amore platonico nel suo senso più puro. Mentre la credenza neoplatonica nella "presenza dello spirituale nel materiale" offriva uno sfondo filosofico al suo entusiasmo estetico ed amoroso per la bellezza, l'opposto aspetto del neoplatonismo, l'interpretazione della vita umana come forma irreale, deviata e tormentosa di esistenza, paragonabile alla vita nell'Ade, era in armonia con l'incommensurabile scontento di se stesso e dell'universo, nel quale consiste la firma stessa del genio di Michelangelo. Come Piero di Cosimo potrebbe chiamarsi l'unico epicureo genuino tra i tanti artisti influenzati da Lucrezio, Michelangelo potrebbe definirsi l'unico platonico genuino tra i molti artisti che il neoplatonismo influenzò."

${ }^{46} \mathrm{Ibidem}$, p. 4. As posições platônicas de Michelangelo se destacam ainda mais facilmente em sua poesia, porém, por uma questão de escolha limitou-se na presente pesquisa a tratar de sua arte plástica.

${ }^{47}$ Anthony Blunt, La Théorie des Arts en Italie 1450-1600, 1988, p. 90. Tradução nossa. "l'influence du néo-platonisme l'amena à croire à la beauté de l'univers, visible avant tout à la beauté humaine, sans que le mysticisme nostalgique de Florence vînt désormais colorer celle-ci". 
iconografia e, especialmente, em seu conteúdo. ${ }^{48}$ Michelangelo buscava na filosofia neoplatônica os símbolos da vida, do destino, e a sensação de transcendência do divino e do espírito que perpassa seus trabalhos. ${ }^{49}$

Para Michelangelo, é a imaginação que leva o artista a apreender não meramente a beleza sensível, mas sim uma forma superior de beleza que é tratada como um reflexo do divino apreendida por meio do mundo material, e neste sentido ele é um neoplatonista espelhando as concepções de Platão sobre a beleza ideal, a forma e o divino, tal como seus contemporâneos.

Curiosamente, tal como Leonardo da Vinci, Michelangelo havia herdado uma tradição científica da pintura e do nu artístico, e junto com ela também uma concepção neoplatônica que permeava os círculos florentinos. De fato, sua pesquisa empírica da natureza, não o leva para o caminho naturalista, mas o que prevalece em sua obra, que se pode ver nas formas é o conceito neoplatônico da beleza.

Esse conceito aparece em Michelangelo por meio do corpo humano, um corpo claramente idealizado, de proporções grandes e heroico. Para entender Michelangelo, é preciso ter em mente que para ele o artista era capaz de apreender uma beleza superior àquela encontrada na natureza, o caminho dos olhos levava a alma a uma aproximação da beleza..$^{50}$

É preciso observar, então, que a questão do nu artístico em Michelangelo é um ponto que exemplifica claramente sua herança platônica. ${ }^{51}$ Isso porque o nu do escultor evoca Dionísio de Siracusa, Platão, Dante e Petrarca, além das concepções claramente influenciadas por Ficino e Pico della Mirandolla, onde há o conceito de nu-ideia oposto ao nu da realidade que parece banal quando exposto diretamente.

\footnotetext{
${ }^{48}$ Exemplos de seu platonismo podem ser encontrados em estátuas como David e sua Pietà.

${ }^{49}$ Erwin Panofsky, Op. Cit.

${ }^{50}$ Teresa Aline Pereira de Queiroz, O Renascimento, 1995.

${ }^{51}$ Renée Arbour, Miguel Ângelo, 1973.
} 
A esse respeito, vide o trecho:

Na obra de Miguel Ângelo o nu apela para o idealismo em oposição ao nu realista, voluptuoso ou investigador, de Boticelli e de Pollajuollo. Para Miguel Ângelo não se trata de despertar a sensualidade do observador ou a curiosidade do anatomista, mas essencialmente de traduzir a beleza e a força. Os seus nus são construções do espírito e, apesar da sua profunda verdade, construções totalmente ideias. Representam a juventude na sua eternidade viva. ${ }^{52}$

O nu de Michelangelo é uma das formas pelas quais a filosofia neoplatônica se expressa. Ocorre por meio do despertar no observador não a sensualidade banal e biológica, mas uma sensualidade que transmite a beleza e a força em sentidos mais puros. Seus nus são construções do espírito e contêm profundas verdades que visam captar a Forma e a ideia. São uma espécie de eternidade encapsulada.

E que seus nus sejam a transmissão de uma Ideia é apenas parte do que o torna um escultor platônico, pois, mais do que transmitir a Verdade e a Ideia, estas só podem ser alcançadas quando libertas, ou seja, quando apresentadas em suas formas puras. Para isso, Michelangelo aponta para uma arte que deve se elevar a Deus, que deve regressar ao grande demiurgo organizador do universo. Os homens são belos, não para responder a um apelo estético, mas porque se assemelham a Deus. ${ }^{53}$

Em Michelangelo, o corpo humano nu é o objeto primordial de estudo do artista, dele e nele pode se observar não meramente a beleza realista, mas também um reflexo da beleza emanada do divino e do espiritual, e sua fascinação pelo corpo se estende até os anos de velhice, quando sua obra já não reflete este divino, mas usa o corpo para comunicar o sentimento de tristeza e tragédia que lhe são muito intensos. ${ }^{54}$

\footnotetext{
52 Ibidem, p. 58

${ }^{53}$ Ibidem.

${ }^{54}$ Anthony Blunt, Op. Cit., 1988.
} 
No que tange à relação entre a filosofia platônica e a obra de Michelangelo, observou-se ainda que:

A alma irradiante na sua beleza sobrenatural está na base do sistema platónico a que aderiu Miguel Ângelo, e ele poderia escrever como enxergo da sua obra a afirmação de Platão, que no seu Fédon proclama que na origem de toda a beleza há necessariamente <<uma beleza primeira que pela sua própria presença torna belas as coisas a que chamamos belas, seja qual for a maneira de que esta comunicação se faça.>> Já antes de Platão os pré-socráticos tinham demonstrado que acima de todas as coisas que se podem dizer belas há a própria Beleza. Mas é em Platão que encontramos a maneira de atingir a beleza ideal, o amor platônico: este meio é o da ascese dialética em direção à ideia do Belo. E Miguel Ângelo frequenta assiduamente esse tríptico constituído pelo Banquete, Fedro e Fédon. A primeira etapa da ascese situa-se no degrau do amor pela beleza do corpo e, generalizando, por todos os corpos belos. $\mathrm{O}$ amor volta-se em seguida por si mesmo para a alma do ser amado e o invólucro carnal perde toda a importância. Só subsiste a beleza da alma. É ultrapassando as formas sensíveis que se atinge a beleza das ocupações da alma, ou seja, da conduta humana, e é a partir da moral que se acederá à moralidade absoluta. A moralidade não constitui um fim em si e só a diversidade dos conhecimentos e a busca da unidade na sua variedade poderá levar à purificação perfeita por meio da ciência. Este caminho para o ideal compreende quatro etapas a partir do amor das formas sensíveis, passando pelo amor das almas e a aquisição da ciência. Estas etapas são com efeito as quatro figuras da beleza; beleza do corpo, beleza moral, beleza intelectual e beleza absoluta. No Fedro, Miguel Ângelo encontrou formulada a descrição desse caminho simbólico. Contemplou a subida da alma para o Belo absoluto. Esta ascensão efectuou-se segundo a elevação de uma espécie de pirâmide ideal, cuja base seria constituída pelas formas sensíveis tais como aparecem e o cimo pelas ideias principais e pela Verdade. Para Miguel Ângelo como para Platão, a ideia do Belo em si corresponde precisamente à imagem de Deus, e são esses princípios que ele tenta fixar no mármore. ${ }^{55}$

Com efeito, Michelangelo compartilha com Platão a noção de que toda a beleza emana da alma, das coisas que são belas em si, e não meramente do belo sensível. A beleza também não é somente física, mas divide-se em quatro esferas: a beleza do corpo, moral, intelectual e absoluta.

Assim como em Platão, para Michelangelo, a beleza também desempenha um papel moral na formação do intelecto, ela é um dos caminhos pelos quais se

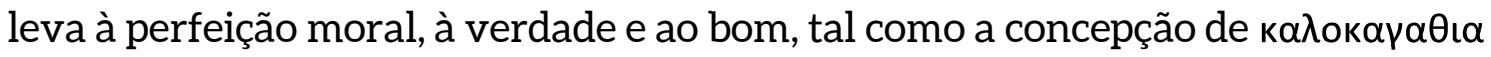

\footnotetext{
${ }^{55}$ Renée Arbour, Op. Cit., 1973, p. 156 a 158.
} 
da antiguidade grega. São esses princípios supremos que ele buscava esculpir cuidadosamente no mármore.

Observa-se que o demiurgo platônico presente no diálogo do Timeu guiou Michelangelo em sua jornada da teoria à prática. ${ }^{56}$ Tal como o demiurgo platônico, o escultor humano imita ou copia o paradigma da Forma suprema e perfeita concebida em sua mente, transpassando-a para a matéria mundana. Contudo, nessa passagem, a escultura feita não é capaz de conter toda a eternidade, porque o mundo no qual se realiza é um mundo temporário e imperfeito, do qual nenhuma completa satisfação pode ser extraída.

Esse espaço contínuo entre o divino e o mundano pode ser visto no teto da Capela Sistina. Nela, a lacuna entre o dedo de Deus e o do homem, mesmo no momento de maior intimidade, nunca é superado, há uma diferença clara e tangível entre o divino e o humano, entre Deus e os meros mortais, e quando isso se desvela, entende-se que a perfeição divina está muito acima de qualquer realização humana. Essa imperfeição humana também é observada na sua escultura, no ato contínuo de insatisfação com a obra, porque ela jamais pode alcançar aquilo que pretende representar, sendo o artista condenado a um Eros platônico irresolúvel.

Outra obra que também apresenta salientemente sua inspiração na filosofia platônica é a tumba de Júlio II, na Capela dos Médici. ${ }^{57}$ De fato, a arte tumular, desde os primórdios da humanidade, tem sido utilizada para manifestar pela arte as crenças metafísicas, vide a obra dos egípcios que glorificavam a vida passada.

Vale destacar ainda as características platônicas presentes também na obra enigmática da Pietà. Embora a obra pareça se aproximar de uma modelagem perfeita, Michelangelo não estava satisfeito com o resultado. ${ }^{58}$ Nada nessa

\footnotetext{
${ }^{56}$ Amihud Gilead, A philosophical approach to the riddle of Michelangelo's Florentine Pietà In Cogent Arts \& Humanities, n.3, 2016.

${ }^{57}$ Erwin Panofsky, Op. Cit., 1975.

${ }^{58}$ Amihud Gilead, Op. Cit., 2016.
} 
estátua sublime o satisfaria inteiramente, porque ele não pode alcançar por completo àquilo a que aspira. Sua Pietà se aproxima da Forma universal, é fria e não expressa emoções porque Maria não é como uma mãe terrena, ela se coloca impassível diante do Cristo morto em seus braços. A respeito da tentativa de destruição da obra, comenta-se:

Tudo isso parece ser perfeitamente platônico. Estar satisfeito com o incompleto, com o imperfeito, deve ser claramente não-platônico. No entanto, a insatisfação platônica pode facilmente levar o artista a destruir ou, pelo menos, a abandonar as obras como inacabadas. [...] Contra o pano de fundo platônico filosófico, podemos entender porque a raiva iconoclasta levou Michelangelo a tentar destruir essa obra-prima. ${ }^{59}$

Assim, observa-se que em diferentes obras Michelangelo parece refletir de forma prática na arte a teoria platônica que esteve em seu contexto intelectual, tal como foi interpretado pelo neoplatonismo e por seus contemporâneos como Ficino. Sem dúvida, há em seus trabalhos um privilégio à medida e à Forma acima de qualquer sentimento.

\section{Conclusão}

Em conclusão ao exposto, observa-se que a filosofia platônica exerceu grande influência entre os renascentistas florentinos do século XV nas mais diversas áreas, da poesia às artes plásticas, sendo que, na última, a figura de Michelangelo se destaca como o grande responsável por transladar a teoria à prática.

Nas obras de Michelangelo, os conceitos platônicos são refletidos nas formas, no uso matemático e na preocupação com a medida, a beleza que tem caráter etéreo e divino, bem como por meio da constante insatisfação do artista

\footnotetext{
${ }^{59}$ Ibidem, p. 5. Tradução nossa. "All this appears to be perfectly Platonic. To be satisfied with the incomplete, with the imperfect, must be clearly un-Platonic. Yet Platonic dissatisfaction may easily drive the artist to destroy or, at least, to abandon the works as unfinished. [...] Against the philosophical Platonic background, we may understand why the iconoclastic rage drove Michelangelo to attempt to destroy this masterpiece."
} 
com sua obra, que jamais alcança o transcendente porque está restrita ao material do mundo sensível e imperfeito.

De fato, por meio de uma análise, por exemplo, do nu-conceito presente nas esculturas de Michelangelo, revelam-se claras as recepções dos comentários e textos platônicos e neoplatônicos de Ficino ou de Pico de la Mirandola - que integravam seu círculo intelectual na Academia em Caraggio. O nu já não remete ao sensível ou ao mundo realista diretamente, mas, pelo contrário, ele é parte da ferramenta que indica a presença do divino, ele é antes uma Ideia.

Assim, conclui-se que as obras de Michelangelo, claramente influenciadas pelo seu meio platônico, lançam nas artes plásticas conceitos que permaneciam até então filosóficos e acadêmicos, sendo levados a um novo nível de compreensão física que obriga o próprio artista a um contínuo estado de insatisfação devido ao embate de sua incapacidade de ser o demiurgo divino, ainda que dele se aproxime, porque a beleza expressa jamais é uma beleza meramente mundana, ela é o reflexo da beleza transcendente.

\section{REFERÊNCIAS}

ARBOUR, Renée. Miguel Ângelo. Cacém: Editorial Verbo, 1973.

BARTLETT, Kenneth R. The Civilization on the Italian Renaissance: a sourcebook. Toronto: University of Toronto Press, 2011.

BLUNT, Anthony. La Théorie des Arts en Italie 1450-1600. Paris: Gérard Monfort Éditeur, 1988.

CASSIN, Barbara. (ed.) Dictionary of untranslatables: a philosophical lexicon. Translated by Steven Rendall, Christian Hubert, Jeffrey Mehlman, Nathaneal Stein, and Michael Syrotinski. Princeton/Oxford: Princeton University Press, 2014. 
CAUQUELIN, Anne. Teorias da Arte. Tradução de Rejane Janowitzer. São Paulo: Martins, 2005.

CASSIRER, Ernst. Eidos and Eidolon: the problem of beauty and art in the dialogues of Plato. In: CASSIRER, Ernst. The Warburg Years (1919-1933): essays on language, art, myth, and technology. Translated and with introduction by S.G.Lofts and A. Calcagno. New Haven/London: Yale University Press, 2013.

CHASTEL, André. Arte e humanismo em Florença na época de Lourenço, o Magnífico: estudos sobre o Renascimento e o Humanismo platônico. Tradução Dorothée de Bruchard, introdução e notas de Luiz Marques. São Paulo: Cosac Naify, 2012.

COMBRONDE, Caroline. Les Platoniciens de l'art à la Renaissance. Revue Philosophique de Louvain. Quatrième série, tome 97, n² 2, p. 268-288, 1999.

GARIN, E. Ricerche sulle traduzioni di Platone nella prima metà del sec. XV. In: Medievo e Rinascimento: studi in onore di Bruno Nardi. Florença: Sansoni, 1955.

GILEAD, Amihud. A philosophical approach to the riddle of Michelangelo's Florentine Pietà. Cogent Arts \& Humanities, n.3, 2016.

HANKINS, James. Plato in the Italian Renaissance. vol. I. New York/Leiden/Köln/Kobenhavn: E.J.Brill, 1990.

HAUSER, Arnold. História social da arte e da literatura. Trad. Álvarez Cabral. São Paulo: Martins Fontes, 1998.

HELLER, Agnes. O homem do Renascimento. Viseu: Editorial Presença, 1982.

MORAVCSIK, Julius. Platão e platonismo: aparência e realidade na ontologia, na epistemologia e na ética. São Paulo: Loyola, 2005.

PANOFSKY, Erwin. Il movimento neoplatonico e Michelangelo. Studi di iconologia: I temi umanistici nell'arte del Rinascimento, Einaudi, 1975. 
PAPPAS, Nickolas. Plato's Aesthetics. In: ZALTA, Edward N. (ed.). The Stanford Encyclopedia of Philosophy. 2017. Disponível em:

<https://plato.stanford.edu/archives/ fall2017/entries/plato-aesthetics/>.

Acesso em 21 mai. 2018.

PLATÃO. A República. Introdução, tradução e notas de Maria Helena da Rocha Pereira. 9. ed. Lisboa: Fundação Calouste Gulbenkian, 2001.

PLATÃO. Lísis, de Platão: tradução, estudo introdutório e notas de Helena Andrade Maronna. [Dissertação apresentada ao Programa de Pós-Graduação em Letras Clássicas da USP]. São Paulo: USP, 2004.

QUEIROZ, Teresa Aline Pereira de. O Renascimento. São Paulo: Editora da Universidade de São Paulo, 1995.

ROSA, Ronel Alberti da. A sombra de Orfeu: o neoplatonismo renascentista e o nascimento da ópera. Porto Alegre: EDIPUCRS, 2010.

VASARI, Giorgio. Vida de Michelangelo Buonarroti: Florentino. Pintor, escultor e arquiteto (1586). Trad. Introd. e comentário de Luiz Marques. Campinas: Editora da Unicamp, 2011.

\section{Referência para citação deste artigo}

HAUBERT, Laura Elizia. Notas sobre a influência platônica em Michelangelo. Revista PHILIA | Filosofia, Literatura \& Arte, Porto Alegre, volume 1, número 2, p. 340 - 363, outubro de 2019. 